\title{
CD8 AND CD45RO T LYMPHOCYTES IN BONE MARROW OF GASTRIC CANCER PATIENTS: CORRELATION WITH DISSEMINATED TUMOR CELLS AND DISEASE OUTCOME
}

\author{
S. Osinsky ${ }^{1^{*}}$, A. Kovelskaya ${ }^{1}$, L. Bubnovskaya ${ }^{1}$, D. Osinsky ${ }^{2}$, S. Merentsev ${ }^{2}$ \\ ${ }^{1}$ R.E. Kavetsky Institute of Experimental Pathology, Oncology and Radiobiology, NAS of Ukraine, Kyiv 03022, Ukraine \\ ${ }^{2}$ Kyiv City Clinical Oncological Center, Kyiv 03115, Ukraine
}

\begin{abstract}
Aim: To evaluate the association between the presence of CD8 and CD45RO T lymphocytes in bone marrow (BM), disseminated tumor cells (DTCs), tumor hypoxia and their impact on disease outcome. Material and methods: 91 naïve gastric cancer (GC) patients were enrolled into the study. DTCs, CD8- and CD45RO-positive T lymphocytes in BM were detected using immunocytochemistry. All patients were thoroughly informed about the study that was approved by the local ethics committee. Statistical analyses were done using NCSS2000/PASS2000 and Prism, version 4.03 software packages. Results: It was detected that 80.5 and $81.3 \%$ of patients had CD8- and CD45RO-positive T cells in BM, respectively. When DTCs were detected in BM, the number of patients with CD8-and CD45RO-positive T cells in BM were 86.1 and 84.4\%, respectively. It was also determined that the number of patients with DTCs in BM with categories $M_{0}$ and $M_{1}$ and with CD8- and CD45RO-positive T cells in BM were 86.2 and 85.7\%, 85.7 and 80.0\%, respectively. The association between DTCs in BM and presence of CD8 and CD45RO T cells lymphocytes in BM was not found. At the same time it was shown the association between presence of CD8 and CD45RO T lymphocytes and survival. The presence of CD8- and CD45RO-positive T cells in BM were accompanied with significantly longer overall survival of patients compared to that of patients without CD8- and CD45RO-positive T cells in BM. Conclusion: Patients with the presence of CD8- and CD45RO-positive $\mathrm{T}$ cells in BM demonstrated better survival of GC patients than those with the absence of these cells in BM. It may be suggested that tumor cells in BM are controlled in a dormant state by T cells in BM, in particular by CD8-positive T cells.
\end{abstract}

Key Words: CD8 T lymphocytes, CD45RO T lymphocytes, bone marrow, disseminated tumor cells, tumor hypoxia, survival.

It is known that tumor cells may be found in the bone marrow (BM) of patients with a variety of malignant tumors categorized as $\mathrm{M}_{0}$ category [1-3]. The tumor cells in BM were named disseminated tumor cells (DTCs) [4]. It was shown that persistence of DTCs in BM is an independent prognostic factor for unfavorable disease outcome $[2,5,6]$. Moreover, there are data that DTCs may persist in the organism within long time without manifestation of disease [5, 7-10]. Such state is known as tumor dormancy that is very intensively studied in many laboratories and clinics [10-14]. Interestingly, that it was suggested some years ago that BM and lymph nodes are privileged sites where tumor cells are controlled in a dormant state by the immune system [15]. Shen et al. [16] mentioned about interesting observation that DTCs derived from a variety of epithelial tumors seem to have a propensity to home to BM, including tumors which do not commonly form bone metastasis, such as colon cancer. This implies that BM might be a reservoir for DTCs from where they may recirculate into circulating system and then colonize in other distant organs. It has been shown that DTCs resist to chemotherapy and hormonal therapy, and survive in BM for years to decades. DTCs are dormant. Dormancy is related to cytostatic drug resistance and may be a property of minimal residual disease and tumor stem cells.

One of the main problems is a question about mechanisms that can control the long-term persistence

Submitted: November 04, 2014.

"Correspondence: $\quad$ E-mail: osion@onconet.kiev.ua Abbreviations used: $\mathrm{BCL}_{1}-\mathrm{B}$ cell lymphoma; $\mathrm{BM}$ - bone marrow; DTCs - disseminated tumor cells; GC - gastric cancer; OS overall survival. of DTCs in BM before the relapse or metastasis. The answer on this question could help to develop the methods to control the tumor dormancy, predict relapse of disease and propose the adequate therapy. In this context there are very important data about the participation of memory T cells occupied BM in the control of tumor dormancy. Farrar et al. [17] have used the murine B cell lymphoma $\left(\mathrm{BCL}_{1}\right)$ as a model of tumor dormancy in mice vaccinated with the BCP1 Ig and demonstrated that CD8-positive, but not CD4-positive, T cells are required for the maintenance of dormancy in BCL1 lg-immunized BALB/c. Authors suggested that CD8-positive T cells via endogenous production of IFN- $\gamma$ in collaboration with humoral immunity can induce and maintain the tumor dormancy. Feuerer et al. [18] have shown that breast cancer patients with DTCs in their BM had more memory CD4 T cells and more $\mathrm{CD} 56^{+} \mathrm{CD} 8^{+}$cells than patients with tumor cell-negative BM. Taking into account obtained results authors hypothesized that "BM is a special compartment for immunological memory and tumor dormancy". Later these authors have shown that BM and tumors of transgenic mice contain high number of CD8-positive T cells specific for the melanoma antigen tyrosinase-related protein and showing mostly effector memory phenotype [19]. It was suggested that thereby memory T cells could control disseminated melanoma cells. Mahnke et al. [20] have suggested that the BM microenvironment has special features for the maintenance of tumor dormancy and immunological T-cell memory. Recent publications presented the data confirming this suggestion [21, 22].

It has to be noted that the publications aimed to find the association between DTCs and memory T cells 
in BM are limited especially in the clinical setting. Many questions are left to be received the answers to clarify the control of tumor dormancy by host immune reactions. Pantel et al. [1] concluded that the role of the immune system in dormancy control and metastatic progression has not been proved.

In gastric cancer (GC) patients DTCs were also found [23]. Our previous study has shown that DTCs were detected in $51.4 \%$ of GC patients with $M_{0}$, and overall survival (OS) of patients with $\mathrm{M}_{0}$ and DTCs was shorter than that of patients without DTCs (patients in both groups were operated only) $(p=0.0497)$ [24]. Taking into account these data and the virtual absence of the data concerning association between memory T cells in BM and DTCs we have aimed to find the possible association between presence both of DTCs and CD8- and CD45RO-positive T cells in BM and evaluate the correlation between CD8- and CD45RO-positive $\mathrm{T}$ cells in $\mathrm{BM}$ and clinical outcome.

\section{MATERIALS AND METHODS}

Patients. A total of 91 patients ( 61 men and 30 women) with primary GC were diagnosed and treated at the City Clinical Oncological Center (Kyiv), during period 2008-2011. No patient received chemotherapy or radiation prior to surgery, and the majority of patients with advanced cancer had received adjuvant chemotherapy. Tissue samples were taken immediately after tumor excision. Tumors were classified and staged according to the 2002 version of the UICC staging system [25]. Histological types of tumor were evaluated by WHO histological classification (2000) [26]. All patients were thoroughly informed about the study that was approved by the local ethics committee.

Detection of tumorcells, CD8-and CD45RO-positive Tcells in BM. Preoperatively, 2.0-3.0 mL of BM aspirates from the sternum with conventional cautions to avoid the hit of skin epithelial cells into the sample was taken into a heparinized syringe and transferred into a tube "Sarstedt" containing EDTA. After ficoll-hypaque density centrifugation (density, 1.077; Sigma-Aldrich, USA) to isolate the mononuclear cell fraction ( $1105 \mathrm{~g}$ for $20 \mathrm{~min}$ ), the interphase was washed twice in phosphate-buffered saline (PBS) with removing of erythrocytes (Uti-Lyse Erythrocyte Lysing Reagent, Dako Cytomation, USA), resuspended to a concentration of $570 \cdot 10^{3}$ cells $/ 30 \mu \mathrm{L}$, and cytocentrifuged on glass slides. Specimens were airdried from 12 to $24 \mathrm{hs}$ and stained immediately or stored at $-20^{\circ} \mathrm{C}$. Detection of tumor cells (cytokeratin-positive cells) in BM cytospins was performed as presented in [24].

For the detection of CD8 and CD45RO T cells in BM cytospin preparations were fixed by formol-acetone solution $(\mathrm{pH} \mathrm{6.6)}$ in accordance with the instruction. Slides were treated by $0.3 \%$ Triton X- 100 solution, washed by PBS and blocking of endogenous peroxidase followed by incubation in 3\% bovine serum albumin to switch off nonspecific reaction antigen-antibody. Cytospins were incubated with primary monoclonal mouse antibodies against CD8 (clone C8/144B, readyto-use, Dako, Denmark) or with primary monoclonal mouse antibodies against CD45RO (clone UCHL1, Sigma, CШA) in optimal dilution (1:400) within $1 \mathrm{~h}$. After washing of primary antibodies slides were processed with PolyVueHRP Detection System Components (Diagnostic BioSystems, USA). Visualization of peroxidase activity was provided by staining with DAB (Dako, Denmark). Cytospins were counterstained by solution of Methyl Green (ready-to-use, Dako, Denmark) within 1-2 min. Cytospins were examined by light microscopy $(\times 1000)$ to detect CD8- and CD45RO-positive T cells.

Tumor hypoxia evaluation by ${ }^{31}$ P NMR spectroscopy. Level of tumor hypoxia was assessed with ${ }^{31} \mathrm{P}$ NMR spectroscopy. ${ }^{31} \mathrm{P}$ NMR spectra of perchloric acid (PCA) tumor extracts were acquired by means of a highresolution Bruker $400 \mathrm{MHz}$ spectrometer (Widebore Ultrashield, AV-400 electronics, Germany) using a probe of $5 \mathrm{~mm}$ inner diameter. All details of method were presented in our earlier publication [27].

Statistical analysis. All statistical analyses were conducted using the NCSS 2000/PASS 2000 and Prism, version 4.03, software packages. Correlations were analyzed with the Pearson correlation coefficient. The $\chi^{2}$ test was performed to determine the correlation between the CD8 and CD45RO status of BM and the clinicopathological characteristics. The survival proportion was estimated by using the Kaplan - Meier method and differences in survival were analyzed with the log-rank test. Prognostic values of relevant variables were analyzed by means of the Cox proportional hazards model using hazard ratio and $x^{2}$ test. Two-tailed $p$ values $<0.05$ were considered statistically significant.

\section{RESULTS AND DISCUSSION}

CD8- and CD45RO-positive cells in BM and their correlation with clinical variables. Individual patient data from a total 91 histological confirmed GC patients were included in this study (Table 1). The median age was 62 years. Overall, 80.5 and $81.3 \%$ of patients had CD8and CD45RO-positive T lymphocytes in BM, respectively. There was no association between presence of CD8or CD45RO-positive T cells in BM and clinicopathological characteristics (Tables 2 and 3). A marked predominance of the number of patients characterized by the presence of CD8- and CD45RO-positive T cells in BM with $\mathrm{M}_{0}$ category on patients with CD8- and CD45RO-positive T cells in $B M$ but with $M_{1}$ category was not statistically significant.

CD8- and CD45RO-positive cells and DTCs in BM. When DTCs were detected in BM the number of patients with BM that was positive to CD8 and CD45RO T cells were 86.1 and $84.4 \%$, respectively. It was also determined that the number of patients with DTCs in BM with categories $M_{0}$ and $M_{1}$ and with CD8and CD45RO-positive T cells in BM was 86.2; 85.7; 85.7 and $80.0 \%$, respectively. It is clearly seen that there is not association between DTCs in BM and presence of CD8 and CD45RO T cells lymphocytes in BM. It may be suggested that entering the tumor cells into BM is not linked with the presence and activity of CD8 and CD45RO T cells in BM, but most likely CD8 and CD45RO T cells determine the subsequent behavior of DTCs. 
Table 1. Patient and tumor characteristics

\begin{tabular}{lc}
\hline \multicolumn{1}{c}{ Characteristics } & Number, 91 (\%) \\
\hline Gender & \\
Male & $61(67.0)$ \\
Female & $30(33.0)$ \\
Age (years) & \\
Median & 62 \\
Range & $26-84$ \\
Tumor location & \\
Upper third & $11(12.1)$ \\
Middle third & $20(22.0)$ \\
Lower third & $53(58.2)$ \\
Total & $7(7.7)$ \\
UICC stage & \\
I & $18(19.8)$ \\
II & $16(17.6)$ \\
III & $28(30.7)$ \\
IV & $29(31.9)$ \\
Histological type & \\
Adenocarcinoma & $65(71.4)$ \\
Mucinous adenocarcinoma & $11(12.1)$ \\
Signet-ring cell carcinoma & $12(13.2)$ \\
Undifferentiated carcinoma & $3(3.3)$ \\
Grade (G) & \\
1 & $5(5.5)$ \\
2 & $19(20.9)$ \\
3 & $60(65.9)$ \\
4 & $7(7.7)$ \\
T-classification & $9(9.9)$ \\
$\mathrm{T}_{1}$ & $13(14.3)$ \\
$\mathrm{T}_{2}$ & $36(39.5)$ \\
$\mathrm{T}_{3}$ & $33(36.3)$ \\
$\mathrm{T}_{4}$ & \\
Nodal involvement & $44(48.4)$ \\
$\mathrm{N}_{0}$ & $47(51.6)$ \\
$\mathrm{N}_{1-2}$ & $75(82.4)$ \\
Distant metastasis & $16(17.6)$ \\
$\mathrm{M}_{0}$ & \\
$\mathrm{M}_{1}$ & \\
\hline & \\
\hline & \\
\hline
\end{tabular}

Table 2. Prevalence of $\mathrm{CD} 8^{+} \mathrm{T}$ cells in $\mathrm{BM}$ of $\mathrm{GC}$ patients by clinical variables

\begin{tabular}{|c|c|c|c|}
\hline \multirow{2}{*}{ Variables } & \multicolumn{2}{|c|}{ Patients with $\mathrm{CD} 8^{+} \mathrm{T}$ cells in $\mathrm{BM}$} & \multirow[b]{2}{*}{$p$} \\
\hline & $\begin{array}{c}\text { present } \\
(\mathrm{n}=62,80.5 \%)\end{array}$ & $\begin{array}{c}\text { absent } \\
(\mathrm{n}=15,19.5 \%)\end{array}$ & \\
\hline \multicolumn{4}{|l|}{ Gender } \\
\hline Male & $39(62.9)$ & $10(66.7)$ & \\
\hline Female & $23(37.1)$ & $5(33.3)$ & \\
\hline \multicolumn{4}{|l|}{ Age (years) } \\
\hline Median (range) & $60.5(26-84)$ & $64.0(29-79)$ & \\
\hline \multicolumn{4}{|l|}{ Tumor location } \\
\hline Upper third & $5(8.1)$ & $1(6.7)$ & 0.1297 \\
\hline Middle third & $16(25.8)$ & $1(6.7)$ & \\
\hline Lower third & 38 (61.3) & $10(66.6)$ & \\
\hline Total & $3(4.8)$ & $3(20.0)$ & \\
\hline \multicolumn{4}{|l|}{ UICC stage } \\
\hline 1 & $9(14.5)$ & $4(26.7)$ & 0.5253 \\
\hline II & $12(19.4)$ & $4(26.7)$ & \\
\hline III & $20(32.3)$ & $4(26.7)$ & \\
\hline IV & $21(33.8)$ & $3(20.0)$ & \\
\hline \multicolumn{4}{|l|}{ Histological type } \\
\hline Adenocarcinoma & $46(74.2)$ & $11(73.4)$ & 0.8192 \\
\hline Mucinous adenocarcinoma & $6(9.7)$ & $2(13.3)$ & \\
\hline Signet-ring cell carcinoma & $7(11.3)$ & $2(13.3)$ & \\
\hline Undifferentiated carcinoma & $3(4.8)$ & 0 & \\
\hline \multicolumn{4}{|l|}{ Grade (G) } \\
\hline 1 & $3(4.8)$ & $1(6.7)$ & 0.3686 \\
\hline 2 & $10(16.1)$ & $5(33.3)$ & \\
\hline 3 & 45 (72.6) & $9(60.0)$ & \\
\hline 4 & $4(6.5)$ & 0 & \\
\hline \multicolumn{4}{|l|}{ T-classification } \\
\hline $\mathrm{T}_{1}$ & $5(8.1)$ & $3(20.0)$ & 0.1648 \\
\hline $\mathrm{T}_{2}$ & $5(8.1)$ & $2(13.3)$ & \\
\hline $\mathrm{T}_{3}$ & $26(41.9)$ & $8(53.4)$ & \\
\hline $\mathrm{T}_{4}$ & $26(41.9)$ & $2(13.3)$ & \\
\hline \multicolumn{4}{|l|}{ Nodal involvement } \\
\hline $\mathrm{N}_{0}$ & $30(48.4)$ & $7(46.7)$ & 0.9097 \\
\hline $\mathrm{N}_{1-2}$ & $32(51.6)$ & $8(53.3)$ & \\
\hline \multicolumn{4}{|l|}{ Distant metastasis } \\
\hline$M_{0}$ & $52(83.9)$ & $13(86.7)$ & 0.7887 \\
\hline$M_{1}$ & $10(16.1)$ & $2(53.3)$ & \\
\hline
\end{tabular}

CD8- and CD45RO-positive cells in BM and hypoxia level in primary tumor. Level of tumor hypoxia assessed by NMR spectroscopy was ranged as follows: if the $\mathrm{PME} / \mathrm{Pi}<1.0$, tumors are characterized by severe hypoxia, $1.0<\mathrm{PME} / \mathrm{Pi}<1.4$ moderate hypoxia, $1.4<\mathrm{PME} / \mathrm{Pi}<2.0$ mild hypoxia, and PME/ $\mathrm{Pi}>2.0$ weak hypoxia (satisfactory oxygenation). The association between presence of CD8- and CD45RO-positive $T$ cells in BM and hypoxia level in tumor was not detected: CD8-positive T cells were found in $81.8 \%$ of patients with tumors characterized by severe and moderate hypoxia and $84.2 \%$ of patients with tumor characterized by mild and weak hypoxia, and CD45RO-positive T cells in 86.7 and $82.6 \%$, respectively. Obtained results have shown that tumor hypoxia do not associate with the presence of CD8 and CD45RO T cells in BM and, probably, do not influence their activity.

Table 3. Prevalence of $\mathrm{CD} 45 \mathrm{RO} 0^{+} \mathrm{T}$ cells in $\mathrm{BM}$ of $\mathrm{GC}$ patients by clinical variables

\begin{tabular}{|c|c|c|c|}
\hline \multirow{2}{*}{ Variables } & \multicolumn{2}{|c|}{$\begin{array}{l}\text { Patients with CD45RO }{ }^{+} \text {T cells } \\
\text { in } \mathrm{BM}\end{array}$} & \multirow{2}{*}{$p$} \\
\hline & $\begin{array}{c}\text { present } \\
(\mathrm{n}=74,81.3 \%)\end{array}$ & $\begin{array}{c}\text { absent } \\
(\mathrm{n}=17,18.7 \%)\end{array}$ & \\
\hline \multicolumn{4}{|l|}{ Gender } \\
\hline $\begin{array}{l}\text { Male } \\
\text { Female }\end{array}$ & 49 (66.2) & $12(70.6)$ & \\
\hline \multicolumn{4}{|l|}{ Age (years) } \\
\hline Median (Range) & $61(26-84)$ & $64(29-81)$ & \\
\hline \multicolumn{4}{|l|}{ Tumor location } \\
\hline Upper third & $10(13.5)$ & $1(5.9)$ & 0.4477 \\
\hline Middle third & $18(24.3)$ & $2(11.8)$ & \\
\hline Lower third & $41(55.4)$ & $12(70.5)$ & \\
\hline Total & $5(6.8)$ & $2(11.8)$ & \\
\hline \multicolumn{4}{|l|}{ UICC stage } \\
\hline I & $15(20.3)$ & $3(17.7)$ & 0.4540 \\
\hline ॥ & $12(16.2)$ & $4(23.5)$ & \\
\hline III & $24(32.4)$ & $4(23.5)$ & \\
\hline IV & $23(31.1)$ & $6(35.3)$ & \\
\hline \multicolumn{4}{|l|}{ Histological type } \\
\hline Adenocarcinoma & $51(68.9)$ & $14(82.3)$ & 0.5153 \\
\hline Mucinous adenocarcinoma & $10(13.5)$ & $1(5.9)$ & \\
\hline Signet-ring ce & $11(14.9)$ & $1(5.9)$ & \\
\hline Undifferentiated carcinoma & $2(2.7)$ & $1(5.9)$ & \\
\hline \multicolumn{4}{|l|}{ Grade (G) } \\
\hline 1 & $4(5.4)$ & $1(5.9)$ & 0.3617 \\
\hline 2 & $15(20.3)$ & $4(23.5)$ & \\
\hline 3 & $49(66.2)$ & $11(64.7)$ & \\
\hline 4 & $23(31.1)$ & $1(5.9)$ & \\
\hline \multicolumn{4}{|l|}{ T-classification } \\
\hline $\mathrm{T}_{1}$ & $6(8.1)$ & $3(17.6)$ & 0.6900 \\
\hline $\mathrm{T}_{2}$ & $11(14.9)$ & $2(11.8)$ & \\
\hline $\mathrm{T}_{3}$ & $30(40.5)$ & $6(35.3)$ & \\
\hline $\mathrm{T}_{4}^{3}$ & $27(36.5)$ & $6(35.3)$ & \\
\hline \multicolumn{4}{|l|}{ Nodal involvement } \\
\hline & $35(47.3)$ & $9(52.9)$ & 0.6745 \\
\hline $\mathrm{N}_{1-2}$ & 39 (52.7) & $8(47.1)$ & \\
\hline \multicolumn{4}{|l|}{ Distant metastasis } \\
\hline$M_{0}$ & $62(83.8)$ & $13(76.5)$ & 0.4750 \\
\hline$M_{1}$ & $12(16.2)$ & $4(23.5)$ & \\
\hline
\end{tabular}

OS of patients with CD8-and CD45RO-positive cells in $\mathbf{B M}$. OS was significantly longer in patients with tumors characterized by the presence of CD8- and CD45RO-positive T cells in BM as compared to patients with the absence of CD8- and CD45RO-positive T cells in BM (log-rank test: $p=0.0343$ and $p=0.0235$, respectively, Fig. 1 and 2). It was also determined that OS in patients with DTCs in BM and with presence of CD8-positive T cells in BM was significantly longer in compared with that in patients with DTCs in BM and without CD8-positive T cells in BM (log rank test: $p=0.0226$, Fig. 3). 


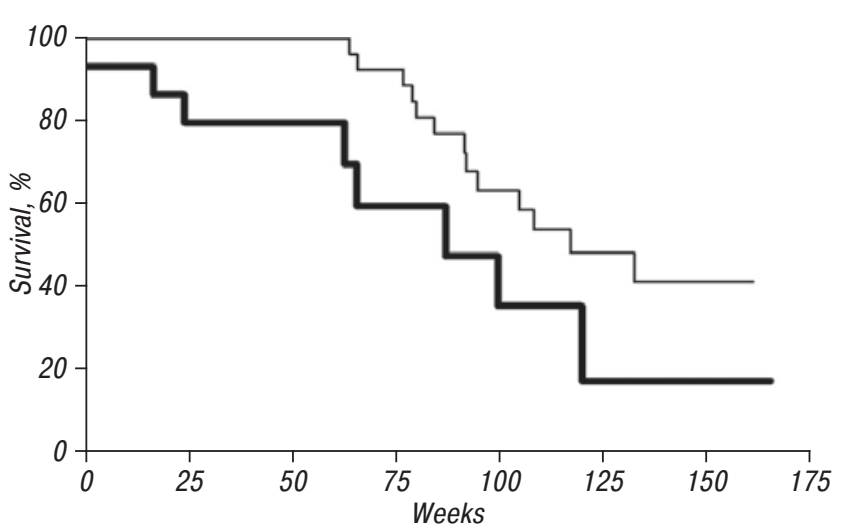

Fig. 1. Kaplan - Meier OS curves for GC patients as a function of $\mathrm{CD}^{+}$presence in $\mathrm{BM}$ (presence of $\mathrm{CD} 8^{+} \mathrm{T}$ cells in $\mathrm{BM}$, thin line; absence of $\mathrm{CD}^{+}$in $\mathrm{BM}$, bold line $\mathrm{p}=0.0343$ ). All patients were analyzed

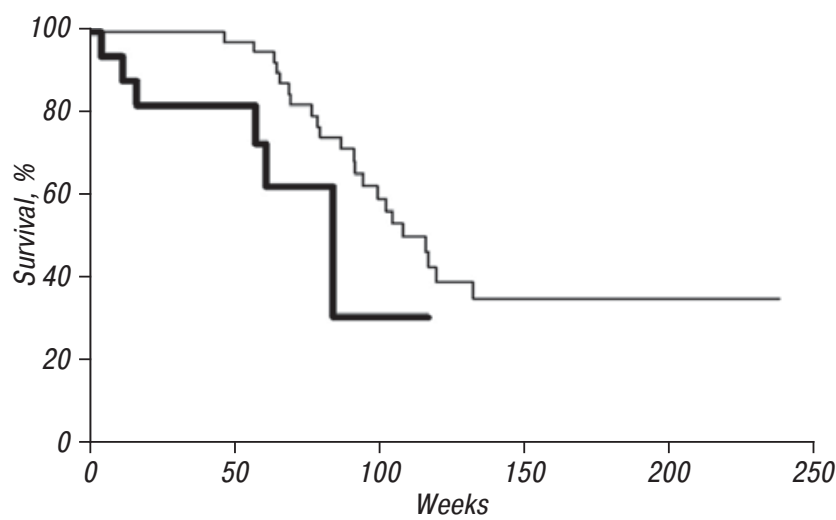

Fig. 2. Kaplan - Meier OS curves for GC patients as a function of $\mathrm{CD} 45 \mathrm{RO}^{+} \mathrm{T}$ cells in $\mathrm{BM}$ (presence of $\mathrm{CD} 45 \mathrm{RO}^{+} \mathrm{T}$ cells in $\mathrm{BM}$, thin line; absence of $\mathrm{CD} 45 \mathrm{RO}^{+} \mathrm{T}$ cells in $\mathrm{BM}$, bold line, $\mathrm{p}=0.0235$ ). All patients were analyzed

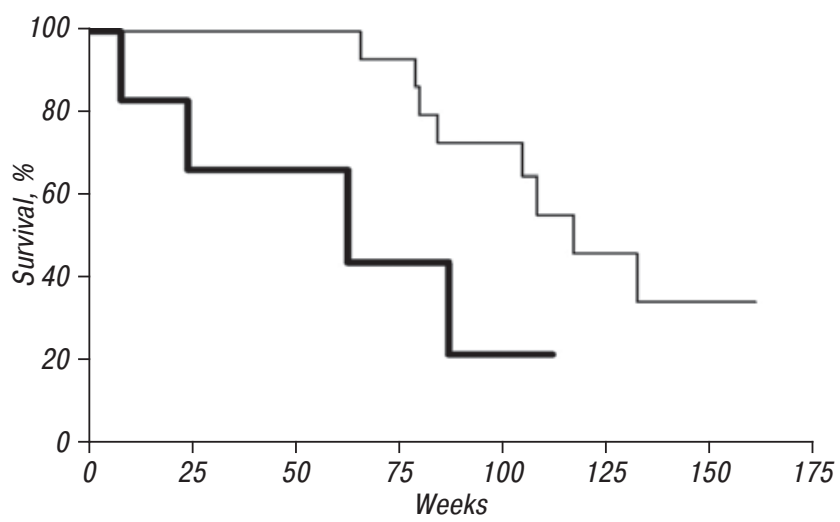

Fig. 3. Kaplan - Meier OS curves for GC patients as a function of $\mathrm{CD}^{+}$presence in $\mathrm{BM}$ (presence of $\mathrm{CD} 8^{+} \mathrm{T}$ cells in $\mathrm{BM}$, thin line; absence of $C D 8^{+}$in $B M$, bold line $p=0.0226$ ). All patients with DTCs in BM were analyzed

The same association was found for CD45ROpositive $T$ cells, but it was not statistically significant (log-rank test: $p=0.0537$, Fig. 4). OS in patients with $M_{0}$ category was also longer in patients with the presence of CD8- and CD45RO-positive T cells in BM, but this link was not statistically significant (log-rank test: $p=0.0538$, Fig. 5 and $p=0.0862$, Fig. 6 , respectively).

Separate analysis of OS in patients with $\mathrm{M}_{0}$ category having DTCs in BM demonstrated that association between the presence of CD8- and CD45RO-positive $\mathrm{T}$ cells in BM and OS was also existed but it was not statistically significant (log-rank rest: $p=0.0674$ and $p=0.9054$, respectively, figures were not presented).
It has to be noted that the association between the presence of CD8- and CD45RO-positive T cells in $\mathrm{BM}$ and $\mathrm{OS}$ in patients who have been treated with operation alone or adjuvant chemotherapy was not statistically significant. It was found only the tendency for the association between the presence of CD8-positive T cells in BM and OS in patients treated with operation alone or with adjuvant chemotherapy (log-rank test: $p=0.0529$ and $p=0.0529$, respectively, figures were not presented). Obtained results have shown the association between the presence of CD8- and CD45RO-positive T cells in BM and OS of patients, in particular OS was statistically longer in all patients with CD8- and CD45RO-positive T cells in BM than that in patients with CD8- and CD45RO-negative $B M$. It is very important to note that OS in patients with DTCs in BM and with CD8-positive T cells in BM was significantly longer than that in patients with CD8negative BM $(p=0.0226)$.

Median follow-up time was 16.0 (range $0.36-54.4$ ) months from diagnosis for all patients. Overall, 31 patients (34.1\%) died during follow-up. In 29 patients (93.5\%) death was related to GC. Of these, $78.3 \%$ of patients had CD8- and $96.6 \%$ of patients had CD45RO-positive T cells in BM. Survival time for patients with the presence of CD8- or CD45ROpositive T cells in BM was $19.6 \pm 1.9$ months and $20.4 \pm 1.5$ months, respectively.

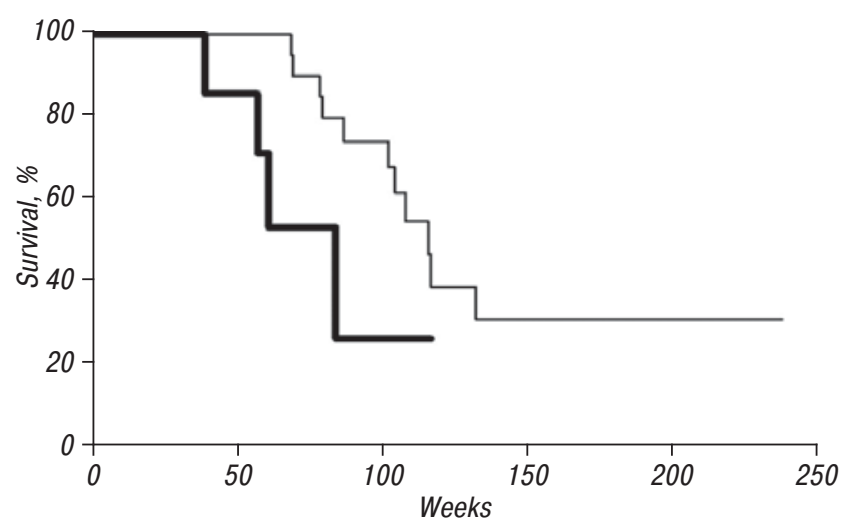

Fig. 4. Kaplan - Meier OS curves for GC patients as a function of $\mathrm{CD}^{2} 5 \mathrm{RO}^{+} \mathrm{T}$ cells in $\mathrm{BM}$ (presence of $\mathrm{CD} 45 \mathrm{RO}^{+} \mathrm{T}$ cells in $\mathrm{BM}$, thin line; absence of $\mathrm{CD} 45 \mathrm{RO}^{+} \mathrm{T}$ cells in $\mathrm{BM}$, bold line, $p=0.0537$ ). All patients with DTCs in BM were analyzed

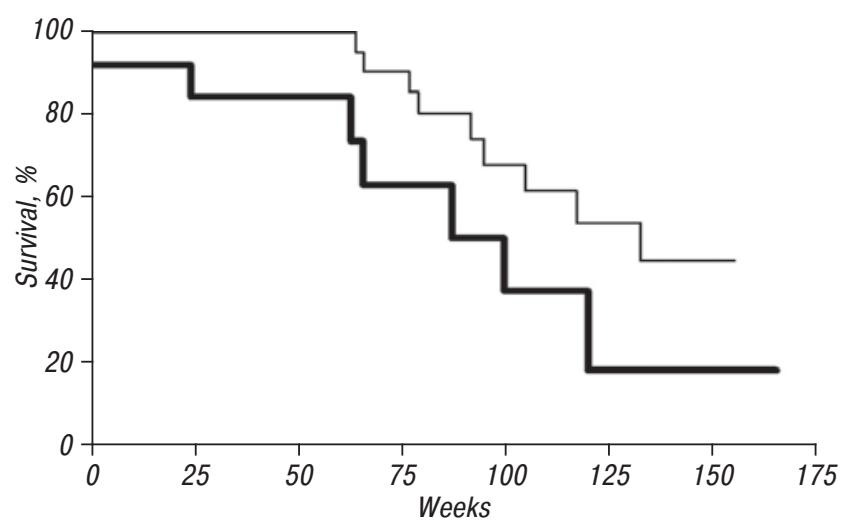

Fig. 5. Kaplan - Meier OS curves for GC cancer patients as a function of $\mathrm{CD} 8^{+}$presence in $\mathrm{BM}$ (presence of $\mathrm{CD} 8^{+} \mathrm{T}$ cells in $\mathrm{BM}$, thin line; absence of $C D 8^{+}$in $B M$, bold line $p=0.0538$ ). All patients with $\mathrm{M}_{0}$ category were analyzed 


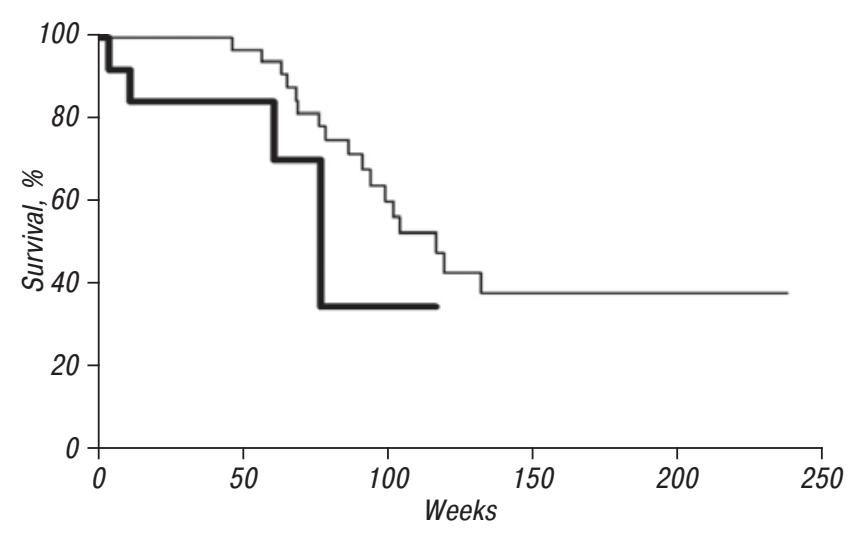

Fig. 6. Kaplan - Meier OS curves for GC patients as a function of $\mathrm{CD} 45 \mathrm{RO}^{+} \mathrm{T}$ cells in BM (presence of CD45RO ${ }^{+} \mathrm{T}$ cells in $\mathrm{BM}$, thin line; absence of $\mathrm{CD}^{4} 5 \mathrm{RO}^{+} \mathrm{T}$ cells in $\mathrm{BM}$, bold line, $p=0.0862$ ). All patients with $M_{0}$ category were analyzed

In conclusion, it may summarized that $80.5 \%$ of GC patients had CD8-positive T cells and $81.3 \%$ had CD45RO-positive T cells in BM. $86.1 \%$ of patients with CD8-positive T cells in BM and $84.4 \%$ of patients with CD45RO-positive T cells had DTC in BM. GC patients with the presence of CD8- and CD45RO-positive $T$ cells in BM demonstrated better OS than those with the absence of CD8- and CD45RO-positive T cells in $\mathrm{BM}$. The results of our investigations and literature data allow to suggest that tumor cells in BM may be existed in a dormant state through the control by T cells, in particular by CD8-positive T cells.

\section{ACKNOWLEDGEMENT}

This research was supported by the National Academy of Sciences of Ukraine (Grants no. 0102U003228).

\section{REFERENCES}

1. Pantel K, Alix-Panabières C, Riethdorf S. Cancer micrometastasis. Nat Rev Clin Oncol 2009; 6: 339-51.

2. Lin H, Balic M, Zheng S, et al. Disseminated and circulating tumor cells: role in effective cancer management. Crit Rev Oncol Hematol 2011; 77: 1-11.

3. Kang Y, Pantel P. Tumor cell dissemination: emerging biological insights from animal models and cancer patients. Cancer Cell 2013; 23: 573-81.

4. Pantel K, Brakenhoff RH, Brandt B. Detection, clinical relevance and specific biological properties of disseminating tumor cells. Nat Rev Cancer 2008; 8: 329-40.

5. Janni W, Vogl FD, Wiedswang G, et al. Persistence of disseminated tumor cells in the bone marrow of breast cancer patients predicts increased risk for relapse - a European pooled analysis. Clin Cancer Res 2011; 17: 2967-76.

6. Tjensvoll $\mathrm{K}$, Olledal $\mathrm{S}$, Heikkilä $\mathrm{R}$, et al. Persistent tumor cells in bone marrow of non-metastatic breast cancer patients after primary surgery are associated with inferior outcome. BMC Cancer 2012; 12: 190.

7. Crowley NJ, Seigler HF. Relationship between diseasefree interval and survival in patients with recurrent melanoma. Arch Surg 1992; 127: 1303-8.

8. Quesnel B. Dormant tumor cells as a therapeutic target? Cancer Lett 2008; 267: 10-7.
9. Sugasawa H, Ichikura T, Ono S, et al. Isolated gastric metastasis from renal cell carcinoma 19 years after radical nephrectomy. Int J Clin Oncol 2010; 15: 196-200.

10. Uhr JW, Pantel K. Controversies in clinical cancer dormancy. Proc Natl Acad Sci USA 2011; 108: 12396-400.

11. Kienle P, Koch M. Minimal residual disease in gastrointestinal cancer. Semin Surg Oncol 2001; 20: 282-93.

12. Koestler WJ, Brodowicz T, Hejna M, et al. Detection of minimal residual disease in patients with cancer: a review of techniques, clinical implication, and emerging therapeutic consequences. Cancer Detect Prev 2000; 24: 376-403.

13. Vessella RL, Pantel K, Mohla S. Tumor cell dormancy. An NCI Workshop report. Cancer Biol Therapy 2007; 6: $1496-504$.

14. Hensel JA, Flaig TW, Theodorescu D. Clinical opportunities and challenges in targeting tumor dormancy. Nat Rev Clin Oncol 2013; 10: 41-51.

15. Müller M, Gounari F, Prifti S, et al. Tumor dormancy in bone marrow and lymph nodes: active control of proliferating tumor cells by CD8 ${ }^{+}$immune T cells. Cancer Res 1998; 58: 5439-46.

16. Shen W, Niu Y, Zhang H. The bone microenvironmental effect in the dormancy of cancer. J Cancer Therapy 2014; 5: 315-22.

17. Farrar JD, Katz KH, Windsor J, et al. Cancer dormancy. VII. A regulatory role for $\mathrm{CD} 8^{+} \mathrm{T}$ cells and IFN- $\gamma$ in establishing and maintaining the tumor-dormant state. J Immunol 1999; 162: 2842-9.

18. Feuerer M, Rocha M, Bai L, et al. Inrichment of memory $\mathrm{T}$ cells and other profound immunological changes in the bone marrow from untreated berast cancer patients. Int J Cancer 2001; 92: 96-105.

19. Umansky V, Abschuetz O, Osen W, et al. Melanomaspecific memory T cells are functionally active in Ret transgenic mice without macroscopic tumors. Cancer Res 2008; 68: 9451-8.

20. Mahnke VD, Schwendemann J, Beckhove P, Schirrmacher V. Maintenance of long-term tumor-specific T-cell memory by residual dormant tumor cells. Immunology 2005; 115: 325-36.

21. Zhao $\mathrm{E}, \mathrm{Xu} \mathrm{H}$, Wang $\mathrm{L}$, et al. Bone marrow and the immunity. Cell Mol Immunol 2012; 9: 11-9.

22. Hensel JA, Flaig TW, Theodorescu D. Clinical opportunities and challenges in targeting tumor dormancy. Nat Rev Clin Oncol 2013; 10: 41-51.

23. Bidard FC, Ferrand FR, Huguet F, et al. Disseminated and circulating tumor cells in gastrointestinal oncology. Crit Rev Oncol Hematol 2012; 82: 103-15.

24. Bubnovskaya L, Kovelskaya A, Gumenyuk L, et al. Disseminated tumor cells in bone marrow of gastric cancer patients: correlation with tumor hypoxia and clinical relevance. J Oncol 2014; 2014: ID582140, 7.

25. International Union Against Cancer, TNM Classification of Malignant Tumors. $6^{\text {th }}$ edn. In: Sobin LH, Wittekind C, eds. New York: Wiley-Liss, 2002.

26. Fenoglio-Preiser C, Carneiro F, Correa P, et al. Gastric carcinoma. In: Hamilton SR, Aaltonen LA, eds. World Health Organization Classification of Tumors. Tumours of the Stomach. Lyon: IARC Press, 2000; chapter 3: 39-52.

27. Osinsky S, Bubnovskaya L, Ganusevich I, et al. Hypoxia, tumour-associated macrophages, microvessel density, VEGF and matrix metalloproteinases in human gastric cancer: interaction and impact on survival. Clin Transl Oncol 2011; 13: 133-8. 